\title{
How Malleable is the Eukaryotic Genome? Extreme Rate of Chromosomal Rearrangement in the Genus Drosophila
}

\author{
José María Ranz, ${ }^{1,2}$ Ferran Casals, ${ }^{1}$ and Alfredo Ruiz ${ }^{1}$ \\ ${ }^{1}$ Departament de Genètica i de Microbiologia, Universitat Autònoma de Barcelona, 08193 Bellaterra (Barcelona), Spain
}

\begin{abstract}
During the evolution of the genus Drosophila, the molecular organization of the major chromosomal elements has been repeatedly rearranged via the fixation of paracentric inversions. Little detailed information is available, however, on the extent and effect of these changes at the molecular level. In principle, a full description of the rate and pattern of change could reveal the limits, if any, to which the eukaryotic genome can accommodate reorganizations. We have constructed a high-density physical map of the largest chromosomal element in Drosophila repleta (chromosome 2) and compared the order and distances between the markers with those on the homologous chromosomal element (3R) in Drosophila melanogaster. The two species belong to different subgenera (Drosophila and Sophophora, respectively), which diverged 40-62 million years (Myr) ago and represent, thus, the farthest lineages within the Drosophila genus. The comparison reveals extensive reshuffling of gene order from centromere to telomere. Using a maximum likelihood method, we estimate that $114 \pm 14$ paracentric inversions have been fixed in this chromosomal element since the divergence of the two species, that is, 0.9-1.4 inversions fixed per Myr. Comparison with available rates of chromosomal evolution, taking into account genome size, indicates that the Drosophila genome shows the highest rate found so far in any eukaryote. Twenty-one small segments (23-599 $\mathrm{kb})$ comprising at least two independent (nonoverlapping) markers appear to be conserved between $D$. melanogaster and $D$. repleta. These results are consistent with the random breakage model and do not provide significant evidence of functional constraint of any kind. They support the notion that the Drosophila genome is extraordinarily malleable and has a modular organization. The high rate of chromosomal change also suggests a very limited transferability of the positional information from the Drosophila genome to other insects.
\end{abstract}

[The sequence data described in this paper have been submitted to the GenBank data library under accession no, AF319441.]

Comparative genomics allows us to infer the rates and patterns of genome evolution. The comparison of genomes between distantly related species is made possible by the construction of high-density linkage and/ or physical maps and will be greatly facilitated and accelerated by the sequencing of entire genomes in a handful of archetypal species. Critical to this approach is that the analysis of linkage (synteny) and order (colinearity) relationships must be based on orthologous coding markers (Type I markers; O'Brien et al. 1997). Comparative mapping has already yielded important insights into how the genomes of plants and mammals have evolved (Paterson et al. 1996; Gale and Devos 1998; O’ Brien et al. 1999).

Drosophila melanogaster was the subject of the first genetic map (Sturtevant 1913) and the first interspecific comparative study (Sturtevant 1921), and is cur-

\footnotetext{
${ }^{2}$ Corresponding author.

Present address: Department of Organismic and Evolutionary Biology, Harvard University, D.L. Hartl Laboratory, Cambridge, MA 02138 , USA.

E-MAIL jranz@oeb.harvard.edu; FAX (617) 496-5854.

Article and publication are at www.genome.org/cgi/doi/10.1101/ gr.162901.
}

rently the genetically best-characterized insect. Its relatively small (180 Mb) genome, whose euchromatic portion $(120 \mathrm{Mb})$ has been recently sequenced and annotated (Adams et al. 2000), is the obligatory reference for comparative genomics in insects. The vast amount of cytogenetic information accumulated over the years on many Drosophila species (Krimbas and Powell 1992; Powell 1997) suggests that the six chromosomal elements (A-F) that constituted the Drosophila ancient genome (Muller 1940; Sturtevant and Novitski 1941) have maintained their integrity in many lineages but have been internally rearranged, most often by the fixation of paracentric inversions. Recent results using DNA markers and in situ hybridization mapping (Whiting et al. 1989; Segarra and Aguadé 1992; Segarra et al. 1995, 1996; Vieira et al. 1997a, 1997b) are consistent with this conclusion. Nevertheless, comparative studies carried out so far either lack resolution or involve only closely related species. Even in the most representative lineages of the genus we still do not know the real extent of chromosomal reorganization and whether or not all chromosomal regions are equally affected. 
We have investigated how the molecular organization of the largest chromosomal element (Muller's element E), has been modified during the 80-124 Myr of separate evolution of the two main lineages in the genus Drosophila, represented by the Drosophila and Sophophora subgenera (Spicer 1988; Russo et al. 1995). The study seeks first to determine the rate of genome reorganization in Drosophila and to compare its dynamics with those of other organisms; second, to help to reconstruct the ancestral Drosophila genome and to detect those regions, if any, whose conservation could be the result of selective constraints; third, to throw light on the limits of genome reorganization; and fourth, to assess the feasibility of transferring positional information from the $D$. melanogaster genome sequence to other, more poorly characterized, insects. This transferability has important practical consequences (cross-genome map-based cloning) for insect species of economic and medical interest.

A detailed physical map of Drosophila repleta chromosome 2 was assembled and its gene arrangement compared with that of the homologous right arm of the metacentric chromosome 3 (3R) of D. melanogaster, whose euchromatic fraction contains $28 \mathrm{Mb}$ of DNA (Adams et al. 2000). D. repleta belongs to the repleta species group of the Drosophila subgenus (Wasserman 1992), whereas D. melanogaster pertains to the Sophophora subgenus (Powell 1997). The complete map encompasses 160 DNA markers precisely mapped to the salivary gland chromosome 2 of $D$. repleta by in situ hybridization and located accurately on the annotated nucleotide sequence of $D$. melanogaster chromosome 3R (Adams et al. 2000). Markers include clones bearing known protein-coding genes, cosmids, and P1 phages. The study also comprises a thorough comparative analysis of four particular chromosomal regions, ranging from $\sim 0.7$ to $1.8 \mathrm{Mb}$, of chromosomal arm 3R. We have thus been able to produce a general picture of the evolution of the entire chromosomal element and to zoom in on certain regions for a finer-scale analysis at the megabase level. Altogether our work represents the most comprehensive genome comparison performed between two insect species so far and has revealed that the Drosophila genome is extraordinarily dynamic and malleable, a finding with important implications.

\section{RESULTS}

\section{Chief Map Features}

Of the 186 DNA probes assayed by in situ hybridization on the polytene chromosomes of $D$. repleta, 154 $(82.8 \%)$ gave positive results providing 158 orthologous markers for comparison (supplemental Table 1, available on-line at http://www.genome.org). Representative examples are provided in supplemental Fig. 1 (available on-line at http://www.genome.org). Among the markers mapped interspecifically, there are genes, cosmids, and P1 phages. Some of our results have been reported previously (Ranz et al. 1997, 1999) and are included here for the sake of completeness only. Two additional genes mapped by other authors, Hsrw (Peters et al. 1984) and orb (H. Naveira, pers. comm.), have been included in the final map. The locations of the 160 markers on chromosome 2 of D. repleta and chromosomal arm 3R of D. melanogaster are shown in Figure 1. Bridges (1935) partitioned the cytological map of chromosomal arm 3R into 20 sections (81-100). All sections have markers (8.4 per section on average) except section 81 . The most proximal and distal markers are P1 phages DS00385 and DS00911, located near the centromere (82E1-2) and close to the telomere (100E1F5), respectively. All markers, without exception, mapped to chromosome 2 of D. repleta (Fig. 1). Thus, this chromosomal element has not been involved in reciprocal translocations or pericentric inversions since the divergence between D. melanogaster and D. repleta, and its gene content has been largely preserved during a total time span of 80-124 Myr. The euchromatic DNA content of chromosomal arm 3R is $\sim 28,000 \mathrm{~kb}$ (Adams et al. 2000). Thus, the average marker density in $D$. melanogaster is 1 per $175 \mathrm{~kb}$. Chromosome 2 represents $\sim 23 \%$ of the euchromatic genome in D. repleta (Wasserman 1992) and holds $35 \mathrm{Mb}$ of DNA (Schulze and Lee 1986). It was divided by Wharton (1942) into 38 divisions; our physical map contains up to 14 markers per division (4.2 on average), and the average marker density is 1 per $219 \mathrm{~kb}$. This density is comparable to that

\footnotetext{
Figure 1 (following page) Large-scale comparison of the gene organization of Muller's element E between Drosophila melanogaster and Drosophila repleta. Connecting lines match the cytological position of orthologous markers. Dashed lines point out those markers whose location can be assigned to a single chromosomal site in $D$. melanogaster but that produce more than one hybridization signal in $D$. repleta. Mapped markers are indicated in blue (genes), green (cosmids), or red (P1 phages). When two or more markers provide redundant mapping information, only representative markers are shown. For precise mapping location of all the markers in $D$. melanogaster and D. repleta, see supplemental Table 1 (available on-line at http://www.genome.org). Red open rectangles indicate the 21 conserved segments comprising at least two independent (nonoverlapping) markers that presumably represent ancient physical associations not disrupted during the evolution of the two compared lineages. Their estimated sizes in $D$. melanogaster are indicated. Two genes localized by other authors, Hsrw (Peters et al. 1984) and orb (H. Naveira, pers. comm.), are also included. Cosmid $200 \mathrm{C} 9$ does not appear as a single marker but as two sets of independent subclones (Ranz et al. 1999). Chromosomal arm 3R of $D$. melanogaster is partitioned into 20 (from 81-100) out of 102 numbered sections in which the D. melanogaster genome is subdivided (Bridges 1935). Chromosome 2 of $D$. repleta shows its seven main lettered sections according to Wharton (1942).
} 


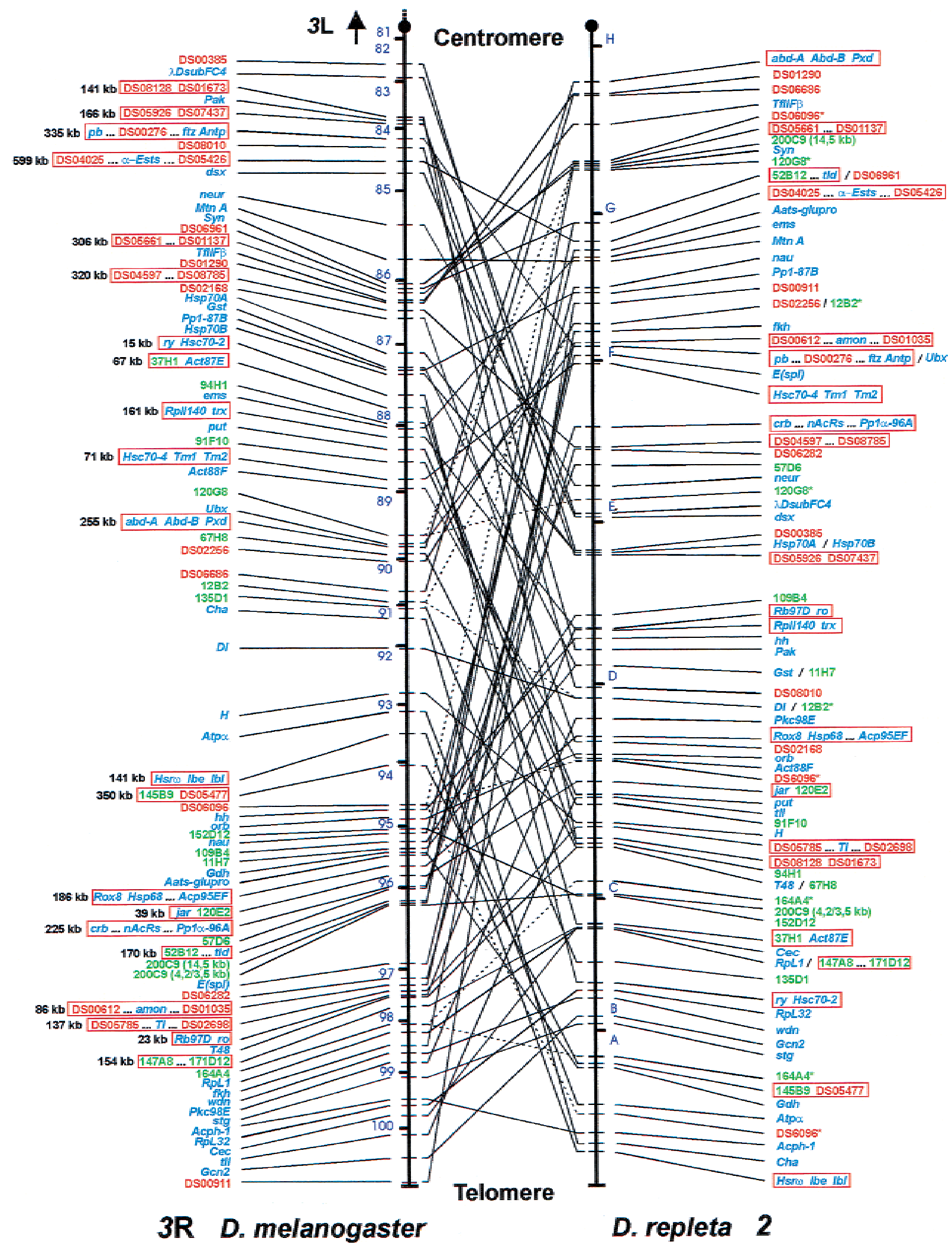

232 Genome Research

www.genome.org 
Table 1. High-Resolution Mapping in Drosophila repleta of Markers from Four Regions of Chromosomal Arm 3R of Drosophila melanogaster

\begin{tabular}{lccccc}
\hline $\begin{array}{l}\text { Chromosomal } \\
\text { region }\end{array}$ & $\begin{array}{c}\text { Size } \\
(\mathbf{M b})\end{array}$ & $\begin{array}{c}\text { Number of } \\
\text { markers }\end{array}$ & $\begin{array}{c}\text { Minimum } \\
\text { coverage }\end{array}$ & $\begin{array}{c}\text { Number of } \\
\text { breakpoints }\end{array}$ & $\begin{array}{c}\text { Density (breakpoints } \\
\text { per Mb) } \pm \text { SD }^{\mathbf{a}}\end{array}$ \\
\hline 83E1-84E1 & 1.814 & 21 & $74.89 \%$ & 6 & $3.31 \pm 1.31$ \\
86A4-E2 & 1.139 & 13 & $81.79 \%$ & 7 & $6.15 \pm 2.27$ \\
95A1-96A23 & 1.217 & 41 & $75.46 \%$ & 12 & $9.86 \pm 2.78$ \\
97B1-E6 & 0.732 & 25 & $74.79 \%$ & 6 & $8.20 \pm 3.30$ \\
Total & 4.902 & 100 & $76.62 \%$ & 31 & $6.32 \pm 1.03$ \\
\hline
\end{tabular}

${ }^{a}$ See González et al. (2000)

obtained in the most refined comparative study performed between man and mouse for the human chromosome 7 (Thomas et al. 2000).

\section{Genome Evolution at the Megabase Level}

Four chromosomal regions of $D$. melanogaster chromosomal arm 3R, going from $\sim 0.7$ to $1.8 \mathrm{Mb}$ in length, have been investigated in great detail (Table 1). The 100 markers mapped in $D$. repleta that come from these D. melanogaster regions yield an average density of one marker per $49 \mathrm{~kb}$ and a minimum coverage of $75 \%$ $82 \%$. The number of disruptions of the marker order in each region provides a minimum estimate of the number of rearrangement breakpoints fixed since the divergence between $D$. melanogaster and $D$. repleta. The breakpoint density thus estimated does not vary significantly among the four regions (Table 1), pointing to a random distribution of breakpoints along chromosome arm 3R of D. melanogaster. Extrapolation of the average density $( \pm S D), 6.32( \pm 1.03)$ breakpoints per $\mathrm{Mb}$, to the entire chromosomal element gives a minimum of $177.07( \pm 28.88)$ breakpoints or $89( \pm 14)$ paracentric inversions fixed in this chromosomal element between D. melanogaster and D. repleta.

\section{Comparative Mapping of Muller's Element E}

The comparison of gene order and distances between D. melanogaster chromosomal arm $3 \mathrm{R}$ and D. repleta chromosome 2 (Fig. 1) indicates that element E has undergone an extensive internal reshuffling that extends throughout its entire length. Both fixation of paracentric inversions and gene transpositions could in principle explain this chromosomal reshuffling. Paracentric inversions are known to be very abundant in Drosophila, both as intraspecific polymorphisms and as interspecific fixed differences (Krimbas and Powell 1992; Powell 1997). However, gene transpositions usually involve a particular class of genes only, those that are tandem repeated, like the histone cluster (Steinemann 1982; Steinemann et al. 1984) or the 5S RNA genes (Alonso and Berendes 1975). This kind of gene is absent from our sample of markers. Furthermore, gene transposition seems to have a very low rate of occur- rence in Drosophila. This was corroborated by comparing the molecular organization of chromosome 2 of $D$. repleta with that of Drosophila buzzatii, another species in the repleta group (data not shown). All changes of location detected can be explained by inversions that are fixed in this chromosome between both species; therefore, on the basis of our sample of 160 markers, no detectable gene transposition has taken place since the divergence between D. repleta and D. buzzatii, 2215 Myr ago (Spicer 1988; Russo et al. 1995). Accordingly, we have considered that paracentric inversions, rather than transposition, are chiefly responsible for the observed pattern of disruption of colinearity.

An unbiased estimate of the number of fixed inversions can be obtained using a maximum likelihood (ML) method (Ranz et al. 1997) that assumes a random distribution of breakpoints along the chromosome in the reference species (D. melanogaster). This assumption seems to hold true in our case (see below). Our ML method, unlike the method of Nadeau and Taylor (1984), does not require a random distribution of markers through the genome. Our sample of markers combines those selected to cover four particular regions, with additional markers spread throughout chromosomal arm 3R. Furthermore, our method makes full use of the information about both conserved and nonconserved chromosomal segments. Application of this ML method to our data (Fig. 1) yielded an estimate of $228( \pm 28)$ fixed breakpoints, that is, $114 \pm 14$ fixed inversions. This rate is consistent with the minimum estimate previously calculated from detailed data at the megabase level as indicated by the wide overlapping of their respective 95\% confidence interval.

Finally, 21 chromosomal segments comprising at least two independent (nonoverlapping) markers have seemingly been conserved between $D$. melanogaster and D. repleta (Fig. 1). These conserved segments are quite small with sizes ranging in $D$. melanogaster from 23-599 kb (188 kb on average).

\section{Colinearity Conservation}

By using nonparametric correlation tests, we deter- 


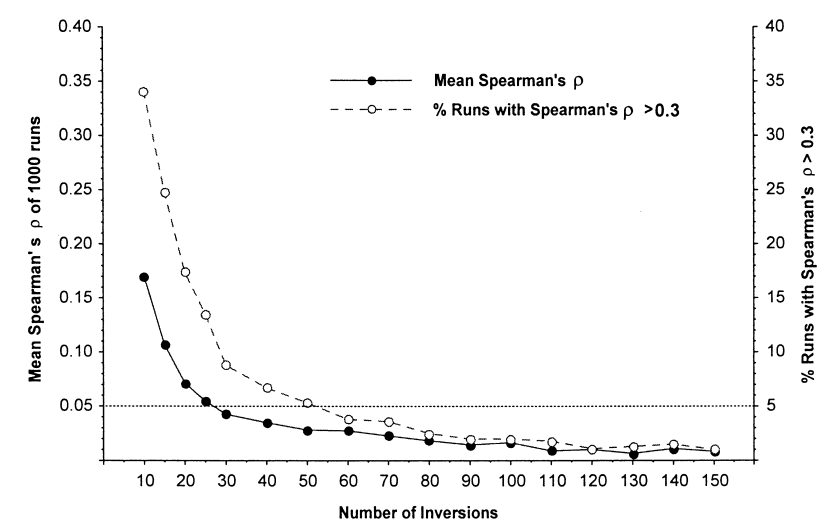

Figure 2. Randomization of chromosomal gene content after fixation of an increasing number of inversions. The conserved segments defined by at least two consecutive and independent markers (nonoverlapping) were considered as a single effective chromosomal site. This yielded a total of 87 positions for the analysis. Solid circles represent the mean values of Spearman's $\rho$ from 1000 runs. Open circles represent the percentages of runs with a Spearman's $\rho>0.3$, that is, a correlation similar to that found between Drosophila melanogaster and Drosophila repleta.

mined whether or not the gene organization of chromosomal element $\mathrm{E}$ has been randomized between $D$. melanogaster and D. repleta. A nonsignificant correlation between the rank order of markers in two species can be taken as evidence of random organization of the gene content of a particular element. In our case, however, a significant correlation of gene order was found between chromosome 2 of $D$. repleta and arm 3R of $D$. melanogaster (four and 10 ties in D. melanogaster and D. repleta, respectively, Spearman $\rho=0.336, P=0.001$; Kendall $\tau=0.217, P=0.003$ ), considering 87 effective chromosomal sites (see Fig. 2 legend for details). This correlation is unexpected given the estimated number of fixed paracentric inversions if these were generated and fixed at random. Computer simulations showed that after fixation of only 60 inversions, the chromosomal gene content is completely randomized in $>95 \%$ of runs, and with 110 inversions, a significant correlation $>0.3$ is only found in $1.8 \%$ of cases (Fig. 2).

\section{DISCUSSION}

\section{Rates of Chromosomal Evolution}

We have estimated that $114 \pm 14$ paracentric inversions have been fixed in Muller's element $\mathrm{E}$ between $D$. repleta and $D$. melanogaster. The low coefficient of variation of this estimate (12\%) and its agreement with the lower bound of $89 \pm 14$ obtained by the in-depth analysis of four particular chromosomal regions support its high reliability. Considering the divergence time between the Drosophila and Sophophora subgenera (Spicer 1988; Russo et al. 1995), we estimate an evolution rate of 0.9-1.4 chromosomal inversions fixed per million years. Table 2 shows a comparison of this rate with those observed in other eukaryotes. We have used the number of disruptions per $\mathrm{Mb}$ per Myr to standardize the data because the genome size and type of chromosomal rearrangements vary among species. Our estimate is similar to that obtained by Segarra et al. (1995), who compared the physical maps of chromosome $X$ between $D$. melanogaster and Drosophila pseudoobscura with a smaller number of markers. Altogether, the estimates in Drosophila show that its genome evolves two orders of magnitude faster than that of mammals and at least fivefold faster than the most dynamic plant genomes, the Arabidopsis-Brassica clade. The limited density of orthologous markers in many comparisons can not explain such a huge disparity in rates of evolution.

Table 2. Rates of Chromosome Evolution in Different Taxa

\begin{tabular}{|c|c|c|c|c|c|}
\hline Comparison & $\begin{array}{l}\text { Chromosomal } \\
\text { disruptions }\end{array}$ & Method & $\begin{array}{l}\text { Divergence } \\
\text { time (Myr) }\end{array}$ & $\begin{array}{l}\text { Genome size } \\
\text { studied (Mb) }\end{array}$ & $\begin{array}{c}\text { Disruption } \\
\text { per Mb per Myr }\end{array}$ \\
\hline \multicolumn{6}{|l|}{ Drosophila melanogaster/ } \\
\hline Drosophila repleta & 228 & RSR & $62^{\mathrm{h}}$ & $28^{m}-35^{n}$ & $0.06567-0.05253$ \\
\hline \multicolumn{6}{|l|}{ Drosophila melanogaster/ } \\
\hline Drosophila pseudoobscura & $112^{\mathrm{a}}$ & NT & $30^{i}$ & $22^{\mathrm{m}, \mathrm{o}}$ & 0.08485 \\
\hline Homo sapiens/Mus musculus & $180^{\mathrm{b}}$ & NT & $114^{j}$ & $3000^{p}-2700^{p}$ & $0.00026-0.00029$ \\
\hline Homo sapiens/Sus scrofa & $35^{c}$ & NT & $93^{j}$ & $3000^{p}-2700^{p}$ & $0.00006-0.00007$ \\
\hline Mus musculus/Sus scrofa & $77^{c}$ & NT & $114^{\mathrm{j}}$ & $2700^{\mathrm{p}}$ & 0.00013 \\
\hline Homo sapiens/Capra hircus & $100^{d}$ & NT & $93^{j}$ & $3000^{p, q}$ & 0.00018 \\
\hline Mus musculus/Capra hircus & $187^{\mathrm{d}}$ & NT & $114^{\mathrm{j}}$ & $2700^{p}-3000^{q}$ & $0.00030-0.00027$ \\
\hline Arabidopsis thaliana/Brassica nigra & $90^{\mathrm{e}}$ & NT & $35^{\mathrm{j}}$ & $120^{r}-360^{e}$ & $0.01071-0.00357$ \\
\hline Lycopersicon/Capsicum ssp. & $22^{f}$ & Direct count & $40^{k}$ & $950^{r}-1900 / 3800^{r}$ & $0.00029-0.00010$ \\
\hline Zea mays/Sorghum bicolor & $15^{9}$ & Direct count & $24^{1}$ & $2500^{r}-760^{r}$ & $0.00013-0.00041$ \\
\hline
\end{tabular}

\section{Genome Research}


Three different factors may contribute to this extreme rate of chromosomal rearrangement in Drosophila: a shorter generation time, a greater mutation rate, and a less detrimental effect on fertility of inversions, which accordingly would have a higher fixation probability. In Drosophila, crossing over is suppressed in males and significantly reduced within the inversion segment in heterokaryotypic females, particularly in case of small inversions, for mechanical reasons (Navarro and Ruiz 1997). Furthermore, single crossovers within the inversion segment produce no inviable zygotes because the resulting unbalanced chromosomes are always set into the polar bodies due to the ordered oogenesis (Sturtevant and Beadle 1936; Carson 1946). Only four-strand double crossovers within the inversion segment, which are likely significant in large inversions only, yield unbalanced gametes (Navarro et al. 1997). However, in mammals and plants, unlike Drosophila, most heterozygotes for chromosomal rearrangements have reduced fertility (White 1973; Burnham 1980).

\section{Patterns of Genome Evolution in Drosophila}

We have detected 21 associations of markers (Fig. 1), which appear to have been conserved since the divergence of $D$. melanogaster and D. repleta, that is, they were present in the genome of their common ancestor. Natural selection might be invoked to explain their preservation, implying that because of functional constraints, the gene organization of these segments can not be disrupted without detrimental consequences. Alternatively, these segments could be the by-product of the fixation of rearrangements with randomly distributed breakpoints (Ohno 1973; Nadeau and Taylor 1984). The random breakage (RB) hypothesis can be tested by computing the probability of recovering by chance a chromosomal segment with a relative size equal to or larger than the observed value: $P=\mathrm{e}^{-2 n l}$, where $2 n$ is the number of fixed inversion breakpoints and $l$ is the relative segment size (Nadeau and Taylor 1984; Ranz et al. 1999). Within the sample of 21 conserved segments detected, only one is large enough $(599 \mathrm{~kb})$ to give a significant result $(P=0.0073)$. However, with 114 fixed inversions, we would expect to find $228 \times 0.0073=1.66$ segments as large as this one in chromosome 2 of $D$. repleta under the RB model. Thus, there is no firm evidence to reject the RB model, that is, evidence for functional constraint. The extraordinary malleability of the Drosophila genome is epitomized by the organization of the Hox complex, which is widely conserved in the animal kingdom (Ruddle et al. 1994). In Drosophila, by contrast, the presumed single Hox ancestral complex has been disrupted at least twice: one split between Antp and $U b x$ took place in the lineage leading to D. melanogaster (Lindsley and Zimm 1992) and the other one between $U b x$ and $a b d-A$ occurred in the lineage leading to D. repleta (Fig. 1) and Drosophila virilis (von Allmen et al. 1996).

Our results point to a modular organization of the Drosophila genome. The proper function of each gene would depend essentially on the physical conservation of its own regulatory sequences located in its immediate vicinity and not on interactions with the surrounding genes. Thus, any module (the gene plus its regulatory sequences) can change its localization within the euchromatin without loss of function. Hox genes appear to be consistent with this view. They are largely autonomous, each with independent regulatory elements apparently insulated from the others (Karch et al. 1994; Hagstrom et al. 1996). Conversely, in vertebrates such genes possess shared regulatory elements, and their regulation seems to require tight colinear clusters (Gérard et al. 1996; Gould et al. 1997). Therefore, there are fewer functional constraints keeping Hox genes together in Drosophila. A few exceptions to this modular organization where two close genes are coregulated have been reported in Drosophila (Andrews et al. 1996; Brogna and Ashburner 1997; Zhang et al. 1999). In these cases, the interaction in cis established between the neighboring genes could prevent chromosomal disruption (Lundin 1993). However, our results suggest that these kinds of interactions are not common, and when they occur must involve genes included in short chromosomal stretches only.

If the Drosophila genome has a modular organization, how can we account for the unexpected correlation found for the gene order between $D$. melanogaster and $D$. repleta? This correlation would be consistent with the existence of underlying functional constraints acting on a regional, rather than local, scale. There is, however, another more parsimonious explanation. If large inversions have a low probability of fixation because of their fertility effects (Navarro et al. 1997), which seems to be the case (Cáceres et al. 1997), then the randomization of gene order would proceed at a slower rate than is implied in Figure 2. Computer simulations with 110 fixed inversions of an allowed relative size not $>30 \%$ of the chromosome yielded correlation coefficients $>0.3$ in $41.2 \%$ of runs (results not shown), which supports this simpler explanation.

\section{Transferability of Positional Information from the D. melanogaster Genome}

Synteny conservation has been reported among mosquitoes and D. melanogaster (Matthews and Munstermann 1994). However, the indispensable condition for a useful transfer of mapping information is the additional conservation of colinearity. The high rate of evolution found in Drosophila limits the transfer of such information from the D. melanogaster genome to other insects. The crucial parameter is the size of the conserved chromosomal fragment, which under the RB 
model is a function of the rate of chromosomal change and the time elapsed since the divergence from the common ancestor. Using the average rate in Drosophila of $\sim 1.85$ disruptions per million years, we have calculated the likelihood of conservation of a chromosomal segment as a function of its size at three different phylogenetic distances, that is, divergence times. The results, shown in Figure 3, are offered as a first approximation only. Variation in evolution rate among chromosomal elements (Vieira et al. 1997a; González et al. 2000) and among phylogenetic lineages should be considered. For example, inversions and translocations are found in different mosquito genera and Chironomus, while only the latter are observed in Ceratitis and Musca (White 1973; Matthews and Munstermann 1994). Nevertheless, some useful predictions can be made. Only nearby genes in D. melanogaster are expected to be still adjacent in different insect orders (Fig. $3)$. This could be the case with engrailed and invected, two genes $15 \mathrm{~kb}$ apart in D. melanogaster (Goldsborough and Kornberg 1994; Adams et al. 2000), which seem to be also together in Bombyx mori (Wu et al. 1999). Information transferability within the genus Drosophila is much easier within the Sophophora subgenus than between different subgenera (Fig. 3). However, even in the latter case, the D. melanogaster genome may be useful over short chromosomal distances. For instance, chromosome 2 of $D$. repleta can be envisaged as a collection of 229 fragments homologous to those in chromosomal arm 3R of D. melanogaster with a predicted average size of $122 \mathrm{~kb}$. Despite this small size, positional information from $D$. melanogaster

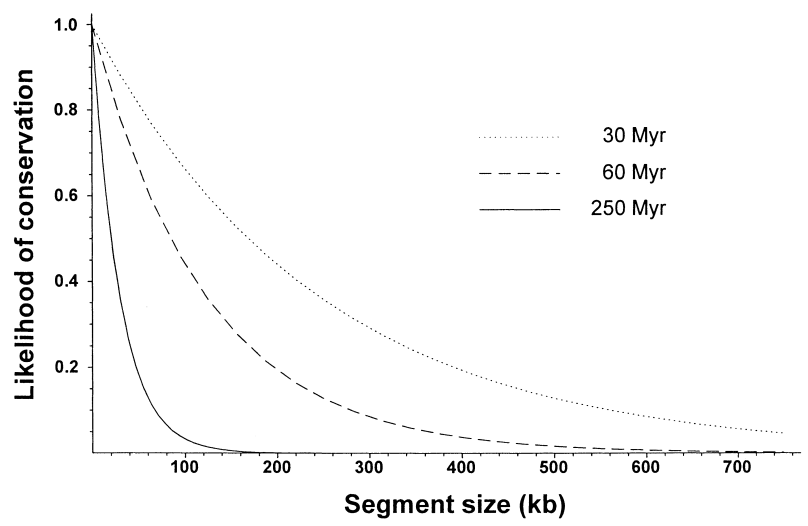

Figure 3. Potential transferability of positional information from Drosophila melanogaster to taxa at different phylogenetic distances. The probability that a chromosomal stretch with a relative length I has not been disrupted after the fixation of $2 n$ breakpoints is $P=e^{-2 n l} .2 n$ depends on the evolutionary divergence time between lineages compared. Divergence times indicated in the chart $\times 2$ were taken from the comparisons among groups of species within the Sophophora subgenus (Throckmorton 1975), among subgenera within the Drosophila genus (Spicer 1988), and among some of the main insect orders (Friedrich and Tautz 1997), respectively. A rate of 1.85 disruptions per Myr was assumed in all cases. was used for cloning purposes in a distantly related species included in the Drosophila subgenus (Cáceres et al. 1999).

\section{METHODS}

\section{Flies}

The following species and stocks were used: D. melanogaster (Canton S), D. repleta (1611.2 and 1611.6 from The National Drosophila Species Resource Center, Bowling Green, Ohio), D. buzzatii (st-1), D. hydei (HY-8), and D. virilis (VIR-Tokyo).

\section{DNA Probes}

Eighty-three gene clones, 51 cosmids, and $52 \mathrm{P} 1$ phages were used as probes. Thirty-seven gene clones and 31 cosmids were hybridized previously (Ranz et al. 1997, 1999), and the remaining clones, 118, have been hybridized in this work. Most gene clones come from genomic or cDNA D. melanogaster libraries and were kindly provided by different authors (supplemental Table 2, available on-line at http://www.genome.org). The $D$. buzzatii double sex $(d s x)$ clone was isolated by PCR (supplemental Table 2), and the PCR product was cloned into a PGEM-T vector (Promega) and sequenced with an ALF express DNA automated sequencer (Pharmacia Biotech). BLASTX (Altschul et al. 1997) gave a probability of matching by chance with $d s x$ sequences from $D$. melanogaster and Bractocera tryoni lesser than E-16, confirming the identity of the cloned sequence (GenBank accession no. AF319441). Cosmids and P1 phages belong to the D. melanogaster libraries of the European (EDGP 2000) and Berkeley (BDGP 2000) Drosophila Genome Projects, respectively. DNA preparation was performed essentially as described in Sambrook et al. (1989) for recombinant plasmids, recombinant phages and cosmids, and as in Hartl and Lozovskaya (1995) for P1 phages.

\section{Construction of the Map and in situ Hybridization}

All clones were hybridized to the salivary gland chromosomes of the source species (D. melanogaster in most cases) as control. When assayed on the chromosomes of $D$. repleta, 63 gene clones (75.9\%), 48 cosmids $(94.1 \%)$, and 43 P1 phages $(82.7 \%)$ yielded detectable hybridization signals (supplemental Table 1). Most clones gave a single signal (see supplemental Fig. 1), but seven gene clones, nine cosmids, and five P1 phages produced two or more hybridization signals. Five of those genes (Act87E, Hsp70A, Hsp70B, Pp1-87B, and $\lambda D s u b F C 4$ ) belong to gene families whose members are conserved and dispersed through the genome. In these cases, as discussed previously (Ranz et al. 1997), the strongest signal invariably corresponds to the chromosomal site of the probed gene. Four markers identified from consistent secondary signals (Hsc70-2, Hsc70-4, Hsp68, and Act88F) were included in the final map. In the case of cosmids and P1 phages that produce several hybridization signals in $D$. repleta, we have considered that the clone encompasses a rearrangement breakpoint fixed during the divergence of $D$. melanogaster and D. repleta as the most likely explanation. Evidence supporting this interpretation has been provided elsewhere (Ranz et al. 1999).

Salivary gland chromosome preparation, probe labeling by nick translation, hybridization, and detection were carried out for all species as described (Ranz et al. 1997) except that hybridization to $D$. repleta chromosomes was performed at 
$25^{\circ} \mathrm{C}$ instead of the usual $37^{\circ} \mathrm{C}$ for control hybridizations. Micrographs were taken by phase contrast with a Nikon Optiphot-1 microscope and a Nikon H-III photomicrographic system at $600 \times$ magnification using EKTAR-25 Kodak film and a blue filter. The localization of probes was determined using the photographic map (Lefevre 1976) and the electron microscopy map (Heino et al. 1994) of D. melanogaster. For D. repleta, we used the map drawn by Wharton (1942).

\section{Analysis of the Degree of Genome Rearrangement}

Given the variable marker density throughout chromosomal arm 3R, the maximum likelihood method described by Ranz et al. (1997), which does not assume any particular marker distribution, was used. To apply this method, markers were anchored in the genome sequence of the reference species, $D$. melanogaster. Then, all the chromosomal segments delimited by neighboring markers were checked for conservation in $D$. repleta and their sizes estimated using precise molecular information (Adams et al. 2000; BDGP 2000). Genes and P1 phages containing STS were easily anchored in the sequence of chromosomal arm 3R and their sizes determined. For some P1 phages and cosmids, molecular information was not available. In these cases, an open reading frame mapped to the same cytological position was used as a reference and assumed to be the midpoint of the clone. When unknown, an average size of 80 and $40 \mathrm{~kb}$ was assumed for P1 phages and cosmids, respectively (Siden-Kiamos et al. 1990; Sternberg 1990; Smoller et al. 1991). Southern analysis and comparison of restriction profiles were performed when necessary to test for the inclusion of a gene within a cosmid or P1 phage or for possible overlap between adjacent clones (see Ranz et al. 1999 for methods). For genes, as well as for cosmids and P1 phages that yielded only one hybridization signal on $D$. repleta chromosome 2, it was assumed that no chromosomal disruption occurred during the evolution of these two lineages, that is, they are conserved. A total of 60 genomic stretches fit into this category, while the remaining 83 were considered nonconserved (seven containing exactly one breakpoint, three exactly two, one exactly three, and 72 at least one).

\section{Computer Simulation}

The randomization of gene order in a chromosome subject to the sequential fixation of paracentric inversions was studied by computer simulation. Briefly, an ideal chromosome consisting of 3500 positions (genes) with the same marker arrangement as in D. melanogaster chromosomal arm 3R was simulated. Increasing numbers of inversions with a random distribution of breakpoints were then generated, and each time Spearman's coefficient of rank correlation between the initial and final marker arrangement was calculated. Each simulation was repeated 1000 times.

\section{ACKNOWLEDGMENTS}

We thank all authors who provided gene clones (supplemental Table 2), and M. Ashburner (Cambridge University) and I. Sidén-Kiamos (FO.R.T.H., Greece) who sent us the P1 phages and cosmids, respectively. We also thank A. Barbadilla, A. Berry, M. Cáceres, D. Hartl, E. Lozovskaya, and J. Parsch for helpful discussions. This work has been supported by DGICT grant PB95-0607 to A.R. and by a FI-UAB doctoral fellowship awarded to F.C.
The publication costs of this article were defrayed in part by payment of page charges. This article must therefore be hereby marked "advertisement" in accordance with 18 USC section 1734 solely to indicate this fact.

\section{REFERENCES}

Adams, M.D., Celniker, S.E., Holt, R.A., Evans, C.A., Gocayne, J.D., Amanatides, P.G., Scherer, S.E., Li, P.W., Hoskins, R.A., Galle, R.F., et al. 2000. The genome sequence of Drosophila melanogaster. Science 287: 2185-2195.

Alonso, C. and Berendes, H.D. 1975. The location of 5S (ribosomal) RNA genes in Drosophila hydei. Chromosoma 51: 347-356.

Altschul, S.F., Madden, T.L., Schaffer, A.A., Zhang, J., Miller, W., and Lipman, D.J. 1997. Gapped BLAST and PSI-BLAST: A new generation of protein database search programs. Nucleic Acids Res. 25: 3389-3402.

Andrews, J., Smith, M., Merakovsky, J., Coulson, M., Hannan, F., and Kelly, L.E. 1996. The stoned locus of Drosophila melanogaster produces a dicistronic transcript and encodes two distinct polypeptides. Genetics 143: 1699-1711.

Arumuganathan, K. and Earle, E.D. 1991. Nuclear DNA content of some important plant species. Plant Mol. Biol. Rep. 9: 208-218.

BDGP. 2000. The Berkeley Drosophila Genome Project database. http://www.fruitfly.org

Bridges, C.B. 1935. Salivary chromosome maps, with a key to the banding of the chromosomes of Drosophila melanogaster. J. Hered. 26: 60-64.

Brogna, S. and Ashburner, M. 1997. The Adh-related gene of Drosophila melanogaster is expressed as a functional dicistronic messenger RNA: Multigenic transcription in higher organisms. EMBO J. 16: 2023-2031.

Burnham, C.R. 1980. Discussions in cytogenetics. C.R. Burnham, MN.

Cáceres, M., Barbadilla, A. and Ruiz, A. 1997. Inversion length and breakpoint distribution in the Drosophila buzzatii species complex: Is inversion length a selected trait? Evolution 51: 1149-1155.

Cáceres, M., Ranz, J.M., Barbadilla, A., Long, M., and Ruiz, A. 1999. Generation of a widespread Drosophila inversion by a transposable element. Science 285: 415-418.

Carson, H.L. 1946. The selective elimination of inversion dicentric chromatids during meiosis in the eggs of Sciara impatiens. Genetics 31: 95-113.

Dear, P.H. 1997. Genome mapping, 1st ed. Oxford University Press, New York.

EDGP. 2000. The European Drosophila Genome Project database. http://edgp.ebi.ac.uk

Ehrlich, J., Sankoff, D., and Nadeau, J.H. 1997. Synteny conservation and chromosome rearrangements during mammalian evolution. Genetics 147: 289-296.

FlyBase 1999. The Drosophila database. Nucleic Acid Res. 24: 53-56.

Friedrich, M. and Tautz, D. 1997. An episodic change of rDNA nucleotide substitution rate has occurred during the emergence of the insect order Diptera. Mol. Biol. Evol. 14: 644-653.

Gale, M.D. and Devos, K.M. 1998. Plant comparative genetics after 10 years. Science 282: 656-659.

Gaut, B. and Doebley, J. 1997. DNA sequence evidence for the segmental allotetraploid origin of maize. Proc. Natl. Acad. Sci. 94: 6809-6814.

Gérard, M., Chen, J.Y., Gronemeyer, H., Chambon, P., Duboule, D., and Zakany, J. 1996. In vivo targeted mutagenesis of a regulatory element required for positioning the Hoxd-11 and Hoxd-10 expression boundaries. Genes \& Dev. 10: 2326-2334.

Goldsborough, A.S. and Kornberg, T.B. 1994. Allele-specific quantification of Drosophila engrailed and invected transcripts. Proc. Natl. Acad. Sci. 91: 12696-12700.

González, J., Betrán, E., Ashburner, M., and Ruiz, A. 2000. Molecular organization of the Drosophila melanogaster Adh chromosomal region in D. repleta and D. buzzatii, two distantly related species of the Drosophila subgenus. Chromosome Res. 8: 375-385.

Gould, A., Morrison, A., Sproat, G., White, R., and Krumlauf, R. 1997. Positive cross-regulation and enhancer sharing: Two 
mechanisms for specifying overlapping Hox expression patterns. Genes \& Dev. 11: 900-913.

Hagstrom, K., Muller, M., and Schedl, P. 1996. Fab-7 functions as a chromatin domain boundary to ensure proper segment specification by the Drosophila bithorax complex. Genes \& Dev. 10: $3202-3215$.

Hartl, D.L. and Lozovskaya, E.R. 1995. The Drosophila genome map: A practical guide. Springer, New York.

Heino, T.I., Saura, A.O., and Sorsa, V. 1994. Maps of the salivary gland chromosomes of Drosophila melanogaster. Dros. Inform. Serv. 73: 621-738.

Janke, A., Feldmaier-Fuchs, G., Thomas, W.K., von Haeseler, A., and Pääbo, S. 1994. The marsupial mitochondrial genome and the evolution of placental mammals. Genetics 137: 243-256.

Johansson, M., Ellegren, H., and Andersson, L. 1995. Comparative mapping reveals extensive linkage conservation-but with gene order rearrangements-between the pig and the human genomes. Genomics 25: 682-690.

Karch, F., Galloni, M., Sipos, L., Gausz, J., Gyurkovics, H., and Schedl, P. 1994. Mcp and Fab-7: Molecular analysis of putative boundaries of cis-regulatory domains in the bithorax complex of Drosophila melanogaster. Nucleic Acids Res. 22: 3138-3146.

Krimbas, C.B. and Powell, J.R. 1992. Drosophila inversion polymorphism. CRC, Boca Raton, FL.

Lagercrantz, U. 1998. Comparative mapping between Arabidopsis thaliana and Brassica nigra indicates that Brassica genomes have evolved through extensive genome replication accompanied by chromosome fusions and frequent rearrangements. Genetics 150: $1217-1228$.

Lefevre Jr., G. 1976. A photographic representation and interpretation of the polytene chromosomes of Drosophila melanogaster salivary glands. In The genetics and biology of Drosophila (ed. M. Ashburner, et al.), pp. 31-66. Academic Press, London.

Lindsley, D.L. and Zimm, G.G. 1992. The genome of Drosophila melanogaster. Academic Press, San Diego.

Livingstone, K.D., Lackney, V.K., Blauth, J.R., van Wijk, R., and Jahn, M.K. 1999. Genome mapping in Capsicum and the evolution of genome structure in the Solanaceae. Genetics 152: $1183-1202$.

Lundin, L.G. 1993. Evolution of the vertebrate genome as reflected in paralogous chromosomal regions in man and the house mouse. Genomics 16: 1-19.

Matthews, T.C. and Munstermann, L.E. 1994. Chromosomal repatterning and linkage group conservation in mosquito karyotypic evolution. Evolution 48: 146-154.

Muller, J.H. 1940. Bearings of the Drosophila work on systematics. In New systematic (ed. J. Huxley) pp. 185-268. Clarendon Press, Oxford.

Nadeau, J.H. and Taylor, B.A. 1984. Lengths of chromosomal segments conserved since divergence of man and mouse. Proc. Natl. Acad. Sci. 81: 814-818.

Navarro, A. and Ruiz, A. 1997. On the fertility effects of pericentric inversions. Genetics 147: 931-933.

Navarro, A., Betrán, E., Barbadilla, A., and Ruiz, A. 1997. Recombination and gene flux caused by gene conversion and crossing over in inversion heterokaryotypes. Genetics 146: 695-709.

Ohno, S. 1973. Ancient linkage groups and frozen accidents. Nature 244: 259-262.

O'Brien, S.J., Wienberg, J., and Lyons, L.A. 1997. Comparative genomics: Lessons from cats. Trends Genet. 13: 393-399.

O'Brien, S.J., Menotti-Raymond, M., Murphy, W.J., Nash, W.G. Wienberg, J., Stanyon, R., Copeland, N.G., Jenkins, N.A., Womack, J.E., and Marshall Graves, J.A. 1999. The promise of comparative genomics in mammals. Science 286: 458-481.

Paterson, A.H., Lan, T.-H., Reischmann, K.P., Chang, C., Lin, Y.-R., Liu, S.-C., Burow, M.D., Kowalski, S.P., Katsar, C.S., DelMonte T.A., Feldmann, K.A., Schertz, K.F., and Wendel, J.F. 1996. Toward a unified genetic map of higher plants, transcending the monocot-dicot divergence. Nat. Genet. 14: 380-382.

Peters, F.P.A.M.N., Lubsen, N.H., Walldorf, U., Moormann, R.J.M., and Hovemann, B. 1984. The unusual structure of heat shock locus 2-48B in D. hydei. Mol. Gen. Genet. 197: 392-398.
Powell, J.R. 1997. Progress and prospects in evolutionary biology: The Drosophila model. Oxford University Press, New York.

Ranz, J.M., Segarra, C. and Ruiz, A. 1997. Chromosomal homology and molecular organization of Muller's elements $D$ and $E$ in the Drosophila repleta species group. Genetics 145: 281-295.

Ranz, J.M., Cáceres, M., and Ruiz, A. 1999. Comparative mapping of cosmids and gene clones from a $1.6 \mathrm{Mb}$ chromosomal region of Drosophila melanogaster in three species of the distantly related subgenus Drosophila. Chromosoma 108: 32-43.

Ruddle, F.H., Bartels, J.L., Bentley, K.L., Kappen, C., Murtha, M.T., and Pendleton, J.W. 1994. Evolution of HOX-genes. Ann. Rev. Genet. 28: $423-442$.

Russo, C.A.M., Takezaki, N., and Nei, M. 1995. Molecular phylogeny and divergence times of Drosophilid species. Mol. Biol. Evol. 12: 391-404.

Sambrook, J., Fritsch, E.F., and Maniatis, T. 1989. Molecular cloning, $A$ laboratory manual, 2nd ed. Cold Spring Harbor Laboratory Press, Cold Spring Harbor, NY.

Schibler, L., Vaiman, D., Oustry, A., Giraud-Delville, C., and Cribiu, E.P. 1998a. Comparative gene mapping: A fine-scale survey of chromosome rearrangements between ruminants and humans. Genome Res. 8: 901-915.

Schibler, L., Vaiman, D., Oustry, A., Guinec, N., Dangy-Caye, A.-L., Billault, A., and Cribiu, E.P. 1998b. Construction and extensive characterization of a goat bacterial artificial chromosome library with three fold genome coverage. Mamm. Genome 9: 119-124.

Schulze, D.H. and Lee, C.S. 1986. DNA sequence comparison among closely related Drosophila species of the mulleri complex. Genetics 113: $287-303$.

Segarra, C., and Aguadé, M. 1992. Molecular organization of the $X$ chromosome in different species of the obscura group of Drosophila. Genetics 130: 513-521.

Segarra, C., Lozovskaya, E.R., Ribó, G., Aguadé, M., and Hartl, D.L. 1995. P1 clones from Drosophila melanogaster as markers to study the chromosomal evolution of Muller's A element in two species of the obscura group of Drosophila. Chromosoma 104: 129-136.

Segarra, C., Ribó, G., and Aguadé, M. 1996. Differentiation of Muller's chromosomal elements D and E in the obscura group of Drosophila. Genetics 144: 139-146.

Siden-Kiamos, I., Saunders, R.D., Spanos, L., Majerus, T., Treanear, J., Savakis, C., Louis, C., Glover, D.M., Ashburner, M. and Kafatos, F.C. 1990. Towards a physical map of the Drosophila melanogaster genome: Mapping of cosmid clones within defined genomic divisions. Nucleic Acids Res. 18: 6261-6270.

Smoller, D.A., Petrov, D., and Hartl, D.L. Characterization of bacteriophage P1 library containing inserts of Drosophila DNA of 75-100 kilobase pairs. Chromosoma 100: 487-494.

Spicer, G.S. 1988. Molecular evolution among some Drosophila species groups as indicated by two-dimensional electrophoresis. J. Mol. Evol. 27: 250-260.

Steinemann, U.M. 1982. Analysis of chromosomal homologies between two species of the subgenus Sophophora: $D$. miranda and $D$. melanogaster using cloned DNA segments. Chromosoma 87: 77-88.

Steinemann, U.M., Pinsker, W., and Sperlich, D. 1984. Chromosome homologies within the Drosophila obscura group probed by in situ hybridization. Chromosoma 91: 46-53.

Sternberg, N. 1990. Bacteriophage P1 cloning system for the isolation, amplification, and recovery of DNA fragments as large as 100 kilobase pairs. Proc. Natl. Acad. Sci. 87: 103-107.

Sturtevant, A.H. 1913. The linear arrangement of six sex-linked factors in Drosophila, as shown by their mode of association. J. Exp. Zool. 14: 43-59.

- 1921. A case of rearrangement of genes in Drosophila. Proc. Nat. Acad. Sci. 7: 235-237.

Sturtevant, A.H. and Beadle, G.W. 1936. The relations of inversions in the $X$ chromosome of $D$. melanogaster to crossing over and disjunction. Genetics 21: 544-604.

Sturtevant, A.H. and Novitski, E. 1941. The homologies of the chromosome elements in the genus Drosophila. Genetics 26: $517-541$.

Thomas, J.W., Summers, T.J., Lee-Lin, S.-Q., Braden Maduro, V.V., Idol, J.R., Mastrian, S.D., Ryan, J.F., Jamison, D.C., and Green,

\section{Genome Research}


E.D. 2000. Comparative genome mapping in the sequence-based era: Early experience with human chromosome 7. Genome Res. 10: 624-633.

Throckmorton, L.H. 1975. The phylogeny, ecology, and geography of Drosophila. In Handbook of genetics (ed. R.C. King), Vol. 3, pp. 421-469. Plenum, New York.

Vieira, J., Vieira, C.P., Hartl, D.L., and Lozovskaya, E.R. 1997a. Discordant rates of chromosome evolution in the Drosophila virilis species group. Genetics 147: 223-230.

- 1997b. A framework physical map of Drosophila virilis based on P1 clones: Applications in genome evolution. Chromosoma 106: $99-107$.

von Allmen, G., Hogga, I., Spierer, A., Karch, F., Bender, W., Gyurkovics, H. and Lewis, E. 1996. Splits in fruitfly Hox gene complexes. Nature 380: 116.

Wasserman, M. 1992. Cytological evolution of the Drosophila repleta species group. In Drosophila inversion polymorphism (ed. C.B. Krimbas et al.), pp. 455-552. CRC, Boca Raton, FL.

Wharton, L.T. 1942. Analysis of the repleta group of Drosophila. University of Texas Publication. 4228: $23-52$.
White, M.J.D. 1973. Animal cytology and evolution. Cambridge University Press, London.

Whiting Jr., J.H., Pliley, M.D., Farmer, J.L., and Jeffery, D.E. 1989. In situ hybridization analysis of chromosomal homologies in Drosophila melanogaster and Drosophila virilis. Genetics 122: 99-109.

Whitkus, R., Doebley, J., and Lee, M. 1992. Comparative genome mapping of shorgum and maize. Genetics 132: 1119-1130.

Wu, C., Asakawa, S., Shimizu, N., and Kawasaki, S. 1999. Construction and characterization of bacterial artificial chromosome libraries from the silkworm, Bombyx mori. Mol. Gen. Genet. 261: 698-706.

Zhang, Y., Roote, J., Brogna, S., Davis, A.W., Barbash, D.A., Nash, D., and Ashburner, M. 1999. Stress sensitive B encodes an adenine nucleotide translocase in Drosophila melanogaster. Genetics 153: 891-903.

Received August 30, 2000; accepted in revised form November 21, 2000. 


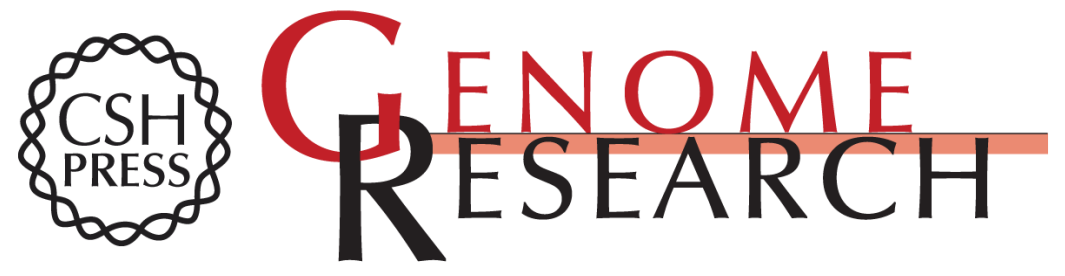

\section{How Malleable is the Eukaryotic Genome? Extreme Rate of Chromosomal Rearrangement in the Genus Drosophila}

José Mari?a Ranz, Ferran Casals and Alfredo Ruiz

Genome Res. 2001 11: 230-239

Access the most recent version at doi:10.1101/gr.162901

Supplemental Material

References

License

Email Alerting Service
http://genome.cshlp.org/content/suppl/2001/02/11/11.2.230.DC1

This article cites 62 articles, 32 of which can be accessed free at: http://genome.cshlp.org/content/11/2/230.full.html\#ref-list-1

Receive free email alerts when new articles cite this article - sign up in the box at the top right corner of the article or click here.

\section{Affordable, Accurate Sequencing.}

